\title{
RESEARCH, PROCESSING AND ANALYSIS OF EXPLOITATION RELIABILITY RESULTS OF HIGH-SPEED RADIAL DIESEL ENGINE
}

\author{
Luka Mihanović $^{1 *}$ - Hrvoje Karna ${ }^{1}$ - Dario Matika ${ }^{1}$
}

${ }^{1}$ Croatian Defense Academy, University of Split, Split, Croatia

\begin{tabular}{|c|c|}
\hline ARTICLE INFO & Abstract: \\
\hline $\begin{array}{l}\text { Article history: } \\
\text { Received: } 27.11 .2020 . \\
\text { Received in revised form: } 8.6 .2020 . \\
\text { Accepted:26.6.2020. } \\
\text { Keywords: } \\
\text { Technical systems } \\
\text { Exploitation reliability } \\
\text { Failure rate } \\
\text { Diesel engine } \\
\text { Minitab } \\
\text { DOI: https://doi.org/10.30765/er.1580 }\end{array}$ & $\begin{array}{l}\text { This paper presents the research on reliability of high-speed radial } \\
\text { marine diesel engine Zvijezda M } 504 \text { B2 based on experimental } \\
\text { data of malfunctions on the engine and time required for repair. } \\
\text { Exploitation reliability and failure intensity were calculated from } \\
\text { operational data collected from the engine log book. Results were } \\
\text { tested by computer program to determine the relevance of the } \\
\text { obtained results. Mathematically calculated reliability model of } \\
\text { high-speed radial marine diesel engine Zvijezda M } 504 \text { B2 showed } \\
\text { continuous increasing function of the intensity of failure and the } \\
\text { fact that the reliability of the engine can be reliably approximated } \\
\text { by Weibull distribution. Based on the obtained results it has been } \\
\text { shown that this distribution, regardless of its complexity, should be } \\
\text { used in practice when calculating reliability of engines with } \\
\text { similar constant and growing malfunction's intensity. The } \\
\text { conclusion is that proposed distribution enables a better depiction } \\
\text { of the observed technical system and the impact of aging of } \\
\text { components on the system reliability. }\end{array}$ \\
\hline
\end{tabular}

\section{Introduction}

High speed radial marine diesel engine Zvijezda M 504 B2 which is powering missile gunboats of the Croatian Navy Fleet is described in this paper as an example of a complex technical system, i.e. the main subsystem of the ship's propulsion system. Marine propulsion system, on average, have a service life of about 20 years and they are required to fulfil high reliability in any work conditions. The basic requirement that is set is the reliability of the marine engine [1], which can be expressed as the number of running hours without malfunction rate. High speed radial diesel engine type M 504 B2 should be capable to operate 2000 working hours without a malfunction, or until an aggregate replacement and general engine revision [2]. Credibility of results of the process of analyzing the efficiency of complex technical systems depends on ability to collect relevant information about their work segments. Experimental data regarding a missile gunboat taken from the Engine Log book [3] is used for the purpose of reliability analysis of high-speed radial marine diesel engines used for ships' propulsion. Ship service regulation prescribes keeping of a logbook for each engine activity and all the work performances. Only defects causing inability to use the system in a proper way were/are considered during the high speed diesel engine M 504 B2 reliability research. All the malfunctions occurred in the ship's engine are recorded in the Engine Log Book and in the Malfunction book which are ultimately updated in the Technical booklet of each engine [4].

\section{Methods}

The general research field in which this study is positioned focuses on the problems of the reliability of the technical systems [5] and in particular the marine diesel engines [6, 7]. The related literature is rich and many papers present systematic reviews, application of models and study results used to evaluate the issues under

\footnotetext{
* Corresponding author.

E-mail address: luka.mihanovic@morh.hr
} 
consideration $[8,9]$. Despite the ongoing efforts, many studies fail to provide the practical benefit to the community. Therefore, further experimental research and analysis of exploitation reliability of engines [10] is considered as a critical element that allows us to reach stable conclusions. The current study presents the method to approximate the reliability of the engine that can be used in practice when calculating reliability of similar marine engines, thus contributing to this area of research.

Experimental data are used as indicators of the technical systems reliability [11] and as the basis for predicting the behavior of similar systems in the future. Future exploitation time and effective preventive maintenance can be accurately predicted by processing marine engines malfunctions experimental data [12], obtained from the Engine Log Book and by calculating reliability functions and failure intensity function of the ship's engine.

Operational conditions of the engine M 504 B2 usage are defined by the operating system profile and environmental conditions. Environmental conditions of the engine M 504 B2 are defined by the conditions in the engine and conditions outside of the engine regarding functioning in the Adriatic Sea, which is the operational area of the Navy ship RTOP type. The observed period of specific propulsion system is 2000 working hours, which includes one complete usage cycle, from installation of the engine till its replacement or the statutory audit, which also defines the operational profile usage of the studied motor [13]. Ship's propulsion system reliability is observed involving many levels: the level of the system, subsystem level and, finally, level of functional components.

\section{Experiment}

Observing, analyzing and forecasting malfunctions can be performed on the level of basic parts (e.g. chippers, spring and housing) or on a unit level (rod seal). It is important to note that the analysis of these effects requires a thorough understanding of characteristics and work capabilities of different system components, as defined by [14].

In this case, ship propulsion system engines were divided into 28 subsystems, based on complex technical system knowledge of high-speed radial diesel engine M 504 B2, analysis of its functioning, analysis of impact of malfunctions on the system providing that the observed system may function properly, as well as analysis of functional links between parts of the system via block diagram system, by respecting the system and subsystems division defined by the manufacturer [15].

During the reliability research of high-speed diesel engine M 504 B2 a total of 6 complex technical systems with 168 sub-systems have been observed and it was found that the malfunction of these systems and subsystems causes the system to stop working. The research time is defined upon the completion of the operation period of each engine to the main audit of 2000 working hours.

Sixty-nine malfunctions, in ten different subsystems, occurred during the research period, creating the disruption of engine's normal operation.

All malfunctions are divided into subsystems with time of occurrence and are presented in Table 1.

\section{Process, analysis and results verification of conducted research}

This research was conducted with the purpose to evaluate and determine whether the Weibull reliability distribution can be effectively used to describe reliability of the high-speed radial diesel engine M 504 B2 as a complex system and that the malfunction intensity is not time-dependent.

In order to achieve the objective, it is necessary to sort, categorize and organize relevant research data that has been collected in the way that is required for the calculation of the reliability function parameters, failure intensity function and suitability maintenance function of diesel engine M 504 B2, Table 2. 
Table 1. Time occurrence of element malfunction of each subsystem for M 504 B2 engine.

\begin{tabular}{|c|c|c|c|c|c|c|c|c|c|c|c|c|c|c|c|c|c|c|c|c|c|c|}
\hline & & \multicolumn{20}{|c|}{ Running hours in 100} & \multirow[b]{2}{*}{ Total } \\
\hline Subsystem & Malfunction & 1 & 2 & 3 & 4 & 5 & 6 & 7 & 8 & 9 & 10 & 11 & 12 & 13 & 14 & 15 & 16 & 17 & 18 & 19 & 20 & \\
\hline \multirow{7}{*}{$\begin{array}{c}\text { Turbocharger } \\
\text { MTBF= } \\
1145.6[\mathrm{~h}]\end{array}$} & Rotor & & & & & & & & & & & & 1 & & & & & & & 1 & & \multirow{7}{*}{13} \\
\hline & $\begin{array}{l}\text { Control } \\
\text { valve }\end{array}$ & & & & & & & & & & & 1 & & & & & & & & & & \\
\hline & Labyrinth & & & & & & & 1 & & & & & & & & & & & 1 & & & \\
\hline & $\begin{array}{l}\text { Gas } \\
\text { router }\end{array}$ & & & & 1 & & & & & & & & & & & & & & & & & \\
\hline & Gasket & & & & & & & & & & & & & & & & & 1 & & & & \\
\hline & $\begin{array}{l}\text { Regulation } \\
\text { screw }\end{array}$ & & & & 3 & & & & 1 & & & & & & & & & & & & & \\
\hline & Housing & & & & & & & & & & & & & & & & 1 & & & & 1 & \\
\hline \multirow{2}{*}{$\begin{array}{c}\text { Reversing } \\
\text { clasp } \\
\text { (Marine ear) } \\
\text { MTBF= } \\
905.6[\mathrm{~h}]\end{array}$} & $\begin{array}{l}\text { Support } \\
\text { clasp }\end{array}$ & & & 1 & & 1 & 4 & 2 & & & 2 & 3 & 2 & & & 1 & 1 & 1 & & & & \multirow[b]{2}{*}{20} \\
\hline & $\begin{array}{l}\text { Housing } \\
\text { clasp }\end{array}$ & & 1 & & & & & & & & & & & & & 1 & & & & & & \\
\hline \multirow{4}{*}{$\begin{array}{l}\text { Cylinder } \\
\text { block } \\
\text { MTBF= } \\
682.12[\mathrm{~h}]\end{array}$} & $\begin{array}{c}\text { Fuel } \\
\text { leakage }\end{array}$ & & & & & & 1 & & & & & & & & & & & & & & & \multirow{4}{*}{6} \\
\hline & $\begin{array}{c}\text { Compression } \\
\text { leakage }\end{array}$ & & 1 & & & & & & & & & & & & & & & & & & & \\
\hline & $\begin{array}{l}\text { Emulsion in } \\
\text { the cylinder }\end{array}$ & & & & & & & & 1 & & & & & & & & & & & & & \\
\hline & $\begin{array}{l}\text { Cylinder } \\
\text { block fuel } \\
\text { leakage }\end{array}$ & & & 1 & & & & 1 & & & & & & & & & & & 1 & & & \\
\hline $\begin{array}{c}\text { Piston } \\
\text { assembly } \\
\text { MTBF= } \\
450[\mathrm{~h}]\end{array}$ & $\begin{array}{l}\text { Piston } \\
\text { damage }\end{array}$ & & & & & 1 & & & & & & & & & & & & & & & & 1 \\
\hline \multirow{2}{*}{$\begin{array}{l}\text { Initiation } \\
\text { system } \\
\text { MTBF= } \\
678.16[\mathrm{~h}]\end{array}$} & $\begin{array}{c}\text { Guide valve } \\
\text { breakage }\end{array}$ & & & & & 1 & & & & & & & & & & & & & & & & \multirow{2}{*}{4} \\
\hline & $\begin{array}{l}\text { Guide valve } \\
\text { blocked }\end{array}$ & & & & & & 2 & & & & & & & 1 & & & & & & & & \\
\hline $\begin{array}{c}\text { Block-pump } \\
\text { fuel } \\
\text { MTBF= } \\
1620[\mathrm{~h}]\end{array}$ & $\begin{array}{l}\text { Fuel } \\
\text { lath }\end{array}$ & & & & & & & & & & & & & & & & & 1 & & & & 1 \\
\hline $\begin{array}{l}\text { Speed } \\
\text { velocity } \\
\text { regulator } \\
\text { MTBF= } \\
1243[\mathrm{~h}] \\
\end{array}$ & $\begin{array}{l}\text { Regulator } \\
\text { spring } \\
\text { breakage }\end{array}$ & & & & & & & & & & & & & 1 & & & & & & & & 1 \\
\hline \multirow{2}{*}{$\begin{array}{c}\text { Exhaust pipe } \\
\text { MTBF= } \\
841.38[\mathrm{~h}]\end{array}$} & $\begin{array}{l}\text { Emulsion } \\
\text { leakage }\end{array}$ & & & & & & & 1 & & & & & & & & & & & & & & \multirow{2}{*}{3} \\
\hline & $\begin{array}{c}\text { Torn } \\
\text { screw }\end{array}$ & 1 & & & & & & & & & & & & & & & & & & 1 & & \\
\hline \multirow{2}{*}{$\begin{array}{c}\text { Injector } \\
\text { MTBF= } \\
719.52[\mathrm{~h}]\end{array}$} & $\begin{array}{l}\text { Nozzle } \\
\text { burned }\end{array}$ & 1 & & & & & & & & & & & & & & & & & & & & \multirow{2}{*}{11} \\
\hline & $\begin{array}{l}\text { Nozzle } \\
\text { leakage }\end{array}$ & 1 & 1 & & & & 1 & 1 & & 1 & 3 & & & & 1 & & 1 & & & & & \\
\hline \multirow{2}{*}{$\begin{array}{c}\text { High } \\
\text { pressure } \\
\text { fuel pump } \\
\text { MTBF= } \\
945.39[\mathrm{~h}] \\
\end{array}$} & $\begin{array}{c}\text { Fuel } \\
\text { leakage }\end{array}$ & 2 & & & & & & & 1 & & & & & & 1 & 1 & 1 & 1 & 1 & & & \multirow[b]{2}{*}{9} \\
\hline & $\begin{array}{l}\text { Managing } \\
\text { mechanism } \\
\text { blocked }\end{array}$ & & & & 1 & & & & & & & & & & & & & & & & & \\
\hline \multicolumn{2}{|c|}{$\begin{array}{c}\text { Total number of } \\
\text { malfunctions }\end{array}$} & 5 & 3 & 2 & 5 & 3 & 8 & 6 & 3 & 1 & 5 & 4 & 3 & 2 & 2 & 3 & 4 & 4 & 3 & 2 & 1 & 69 \\
\hline
\end{tabular}


Well-known mathematical methods, reliability theory relations and MiniTab16 software program will be used for this purpose. Applied analytical models and analytical instruments with suitable software are used to determine appropriate parameters, test and verify the results.

For technical systems renewed by maintenance procedures or repairs i.e. in case of repairable system, the expected time without failure is known as mean time between failures (MTBF) and is calculated according to the equation [16], [17]:

Table 2. Malfunction data of marine diesel engine M 504 B2.

\begin{tabular}{|c|c|c|c|c|c|c|c|c|c|c|}
\hline$n$ & 1 & 2 & 3 & 4 & 5 & 6 & 7 & 8 & 9 & 10 \\
\hline$t_{i}$ & 31.15 & 55 & 57 & 76 & 95 & 107.5 & 149 & 153 & 291.4 & 266.3 \\
\hline$n$ & 11 & 12 & 13 & 14 & 15 & 16 & 17 & 18 & 19 & 20 \\
\hline$t_{i}$ & 318.4 & 337.35 & 338.4 & 370.4 & 380.55 & 439.3 & 450 & 491.5 & 504.35 & 520 \\
\hline$n$ & 21 & 22 & 23 & 24 & 25 & 26 & 27 & 28 & 29 & 30 \\
\hline$t_{i}$ & 525 & 534 & 536.2 & 540 & 558 & 585 & 603.5 & 613 & 613 & 628 \\
\hline$n$ & 31 & 32 & 33 & 34 & 35 & 36 & 37 & 38 & 39 & 40 \\
\hline$t_{i}$ & 638.4 & 643 & 725 & 730 & 780 & 850 & 925 & 930 & 960 & 970 \\
\hline$n$ & 41 & 42 & 43 & 44 & 45 & 46 & 47 & 48 & 49 & 50 \\
\hline$t_{i}$ & 976 & 1040 & 1041 & 1080 & 1090 & 1120 & 1135 & 1200 & 1235 & 1243 \\
\hline$n$ & 51 & 52 & 53 & 54 & 55 & 56 & 57 & 58 & 59 & 60 \\
\hline$t_{i}$ & 1300 & 1370 & 1450 & 1470 & 1490 & 1520 & 1535 & 1568 & 1590 & 1620 \\
\hline$n$ & 61 & 62 & 63 & 64 & 65 & 66 & 67 & 68 & 69 & \\
\hline$t_{i}$ & 1670 & 1698 & 1698 & 1724 & 1725 & 1780 & 1870 & 1880 & 1900 & \\
\hline
\end{tabular}

$$
M T B F=\frac{1}{n} \sum_{i=1}^{n} t_{i}
$$

where $n$ is the number of technical systems, and $t_{i}$ is the $i_{t h}$ technical system malfunction occurrence time.

In case of high-speed diesel engine M $504 \mathrm{~B} 2$, where $n_{d m}=69$, according to Table 2 , the mean time between failures, or mean time of operation without an engine malfunction is:

$$
M T B F_{d m}=\frac{61336.7}{69}=888.94 \approx 890[h]
$$

Operational availability of a technical system is a probability that the system, when used under specified conditions, will function satisfactorily at any point of time, irrespective of time usage. Operational availability is determined by the equation [15]:

$$
O_{r}=\frac{t_{k}}{\left(t_{k}+t_{z}\right)}
$$

In case of the considered diesel engine, the operational availability amounts:

$$
O_{r d m}=\frac{61336.7}{(61336.7+76663.3)}=0.44
$$

The same result for the operational availability can be obtained if the mean time of operation without malfunction (MTBF) is divided by total working time before the main repair planned for the engine.

$$
O_{r d m}=\frac{888.94}{2000}=0.44
$$


Well known mathematical expressions [16] will be used for determining the malfunction density function, malfunction intensity and reliability on the basis of gathered experimental data. The total reliability research interval is in the range from 0 to 2000 hours. Also, at any point of time $t$, there will be $n_{1}(t)$ technical systems that are not cancelled, as can be read from Table 1 . When the time intervals $\Delta t_{j}$ are equal, their optimal number $\mathrm{k}$ can be determined on the basis of Eq. 3, [16]:

$$
k=1+3.3 \log n_{2}
$$

where $n_{2}$ is the total number of malfunctions.

For the total number of malfunctions which is defined during the engine operation, research of the $n_{d m}=69$, optimal number of time intervals $k_{d m}$ amounts:

$$
k=1+3.3 \log 69=7.068 \approx 7
$$

Therefore, the time interval $\Delta t_{j}^{d m}$ is:

$$
\Delta t_{j}^{d m}=\frac{t_{p}}{7}=\frac{2000}{7}=285.7 \approx 285[h]
$$

Using the data from Table 2 (experimental data regarding malfunction of the engine which have been obtained during conducted research on the use of radial high-speed marine diesel engine M-504 B2 and extracted from the documentation) and calculations we were able to gain additional results.

These results are presented in following diagrams: Figure 1 is showing malfunction experimental density function, Figure 2 malfunction intensity, while Figure 3 shows reliability of high-speed radial diesel engine M $504 \mathrm{~B} 2$ in the range of work research of complex technical systems.

Specific number of technical systems in mechanical engineering, as in case of a high-speed radial marine diesel engine, shows a growing failure tendency intensity over time. The Weibull distribution provides the most accurate analysis of such failures modes of the system.

\section{Approximation based on the Weibull distribution function}

If it is assumed that the density function cancellation $f(t)$ has a Weibull distribution, then the hypothesis $H_{0}$ shall be:

$$
R(t)=R_{v}(t)
$$

Alternative hypothesis $H_{l}$ shall be:

$$
R(t) \neq R_{v}(t)
$$

where

$$
R_{v}(t)=e^{-\left(\frac{t-\gamma}{\eta}\right)^{\beta}}
$$




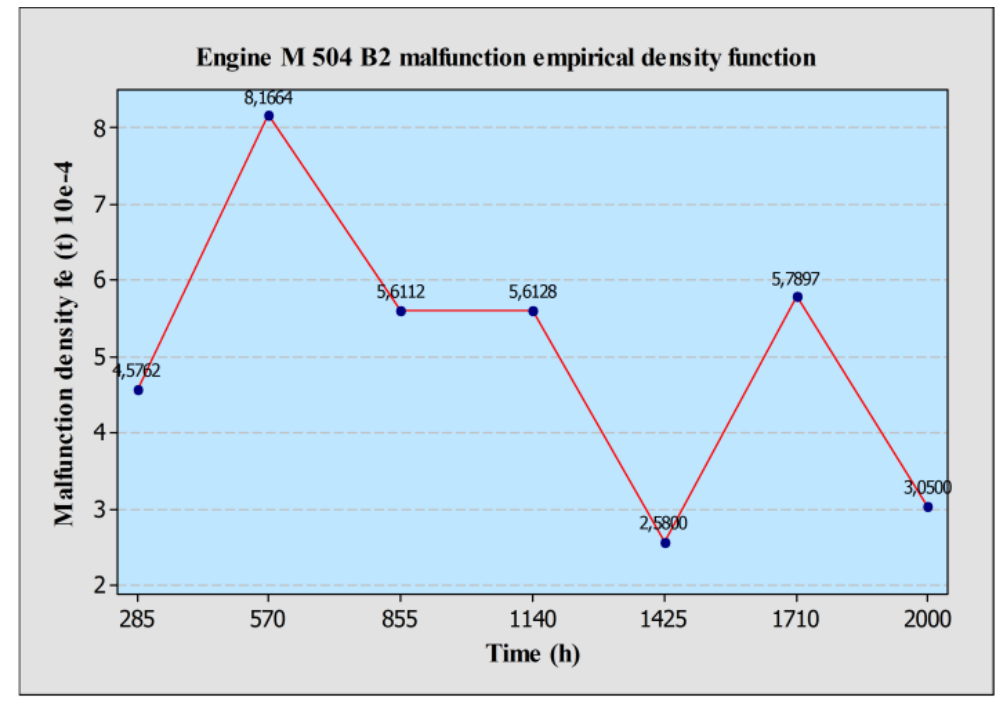

Figure 1. Engine M 504 B2 malfunction experimental density function.

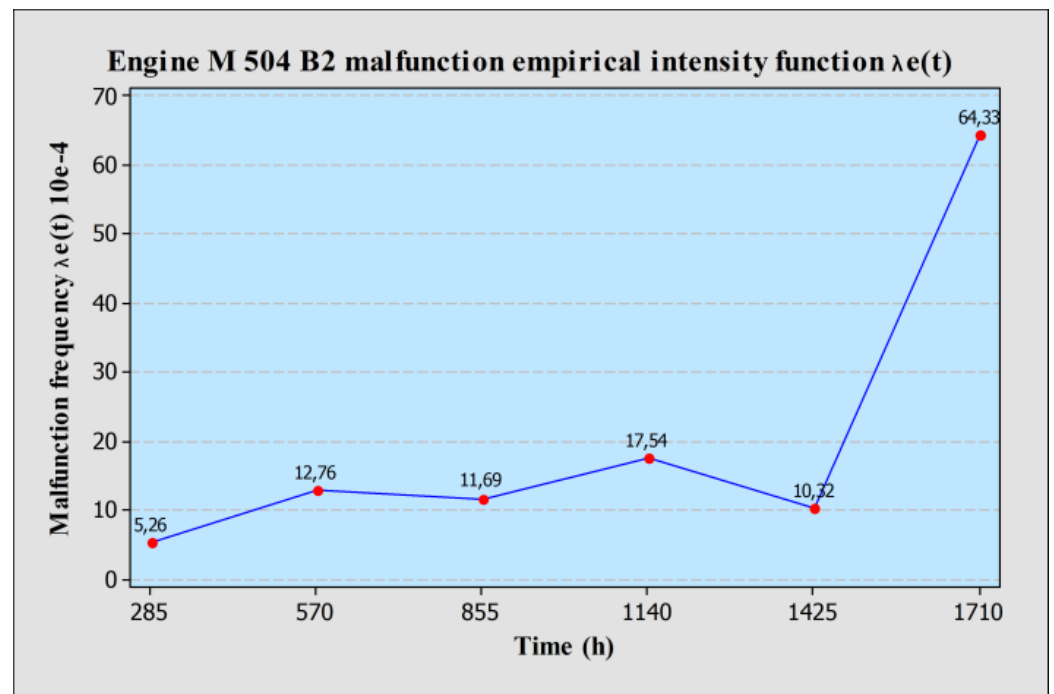

Figure 2. Engine M 504 B2 malfunction experimental intensity function $\lambda_{e}(t)$.

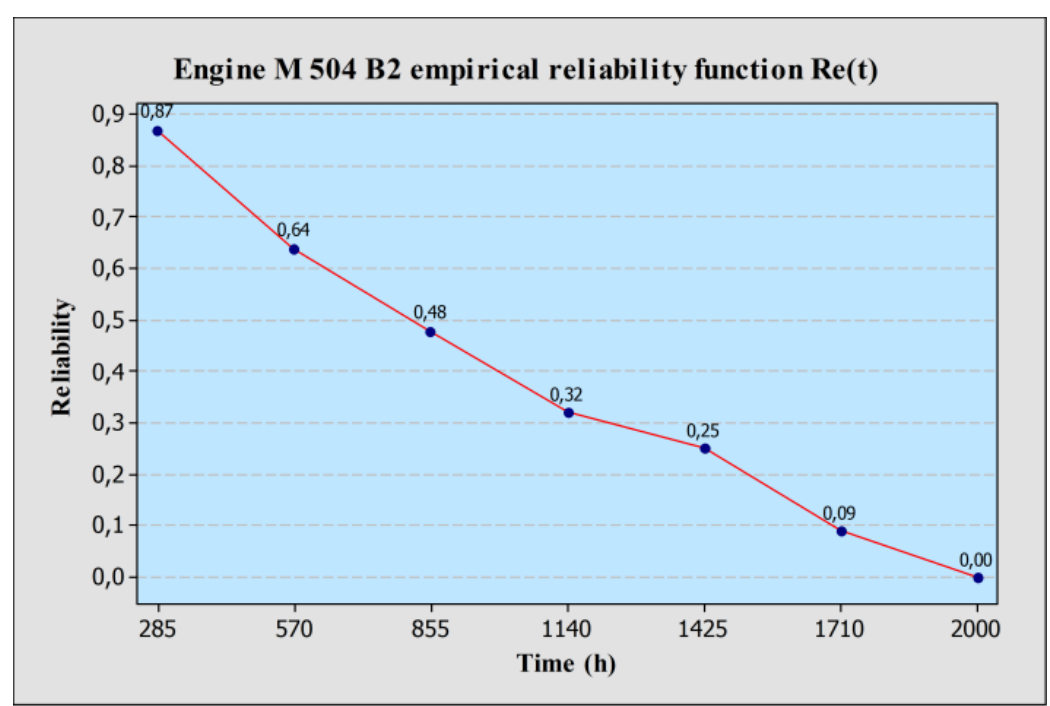

Figure 3. Engine M 504 B2 experimental reliability function $R_{e}(t)$. 
while $\gamma$ is the position parameter, $\beta$ is the shape parameter and $\eta$ is the scale parameter.

The methods used for determining the distribution for approximation of experimental data are divided into two main groups: graphical and analytical. Graphical methods are simpler and often used in engineering practice, and have been applied in this study, too. The research results and proposed hypothesis will be analyzed using graphical methods while the results will be tested using the Minitab analytical software [18].

In general, a graphical method consists of drawing of a graph i.e. diagram with experimentally determined data and data obtained on the basis of the assumed distribution which approximates experimental data.

In the analyzed case, the Weibull distribution is assumed to be a good model for the information given in Table 3 , providing that the plotted points can be well approximated by a straight line. Otherwise, the model is inadequate. Using this procedure, the validity of the assumed model can be evaluated and the parameters of the distribution can be estimated. The first step is to estimate the parameter $\gamma$ based on the mean radians for a given sample size [19], [20]. In case of a large sample size of the mean radians, MR is calculated according to Eq. 12:

$$
M R_{i} \approx \frac{i}{n+1}
$$

where $i$ is the number of failures and $n$ is the sample size.

Having determined the mean radian, the function is lined $g\left(t_{i}, M R_{i}\right)$, and if the same can be approximated by a straight line, then $\gamma=0$. Figure 4 shows the graph of the function $g\left(t_{i}, M R_{i}\right)$.

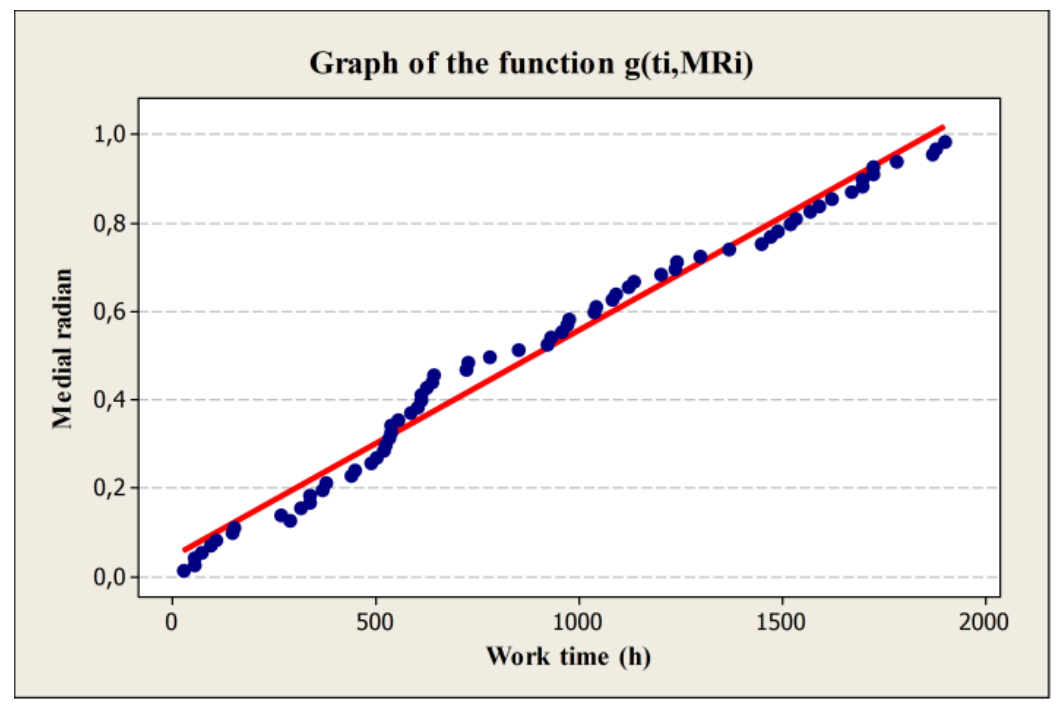

Figure 4. Mean radian.

As the function $g\left(t_{i}, M R_{i}\right)$ can be approximated by a straight line, the reliability function $R_{v}(t)$ takes the following form:

$$
R_{v}(t)=e^{-\left(\frac{t}{\eta}\right)^{\beta}}
$$

Respectively, malfunction intensity function equals to:

$$
\lambda_{v}(t)=\frac{\beta}{\eta} *\left(\frac{t}{\eta}\right)^{\beta-1}
$$

where $\beta>0$ and $\eta>0$. 
The system reliability function described by the expression (12) is mathematically suitable neither for approximation of the experimentally obtained results nor for determining the parameters $\beta>0$ and $\eta>0$. Therefore, by applying the mathematical logarithms operation (natural logarithm ln), Eq. 13 is transformed in the form [21]:

$$
y=\beta * x+c
$$

where

$$
\begin{gathered}
y=\ln \left[-\ln R_{y}(t)\right] \\
x=\ln t \\
c=-\beta \ln \eta
\end{gathered}
$$

The values $y_{j}=y\left(t_{j}\right)$ and $x_{j}=x\left(t_{j}\right)$ can be calculated according (17) and (18) based on the experimental data presented in Table 2. It should be noted that the value of the point $t=2000$ is not taken into consideration because the $R(2000)=0$. The results are shown in Table 3 .

Table 3. Values $x_{j}, y_{j i}, y_{j v}=y_{j}(\hat{\beta}, \hat{c})$.

\begin{tabular}{|c|c|c|c|}
\hline$t_{j}$ & $x_{j}$ & $y_{j}$ & $y_{j v}=y_{j}(\hat{\beta}, \hat{c})$ \\
\hline 285 & 5.652489 & -1.97139774 & -2.00689 \\
\hline 570 & 6.345636 & -0.80679281 & -0.90409 \\
\hline 855 & 6.751101 & -0.30928825 & -0.259 \\
\hline 1140 & 7.038784 & 0.1305319 & 0.198705 \\
\hline 1425 & 7.261927 & 0.32663426 & 0.553726 \\
\hline 1710 & 7.444249 & 0.87877394 & 0.8438 \\
\hline 2000 & 7.600902 & 0 & 1.093036 \\
\hline
\end{tabular}

As the expression (15) is a mathematical description of the direction function, the parameter $\beta$ is actually direction coefficient. $\beta$ can be calculated from the expressions (19), and the parameter $c$ based on the expression (15), when the parameter is defined as $\beta=\hat{\beta}$, then the following expression is valid (20):

$$
\begin{gathered}
\hat{\beta} \approx \frac{\Delta y_{j}}{\Delta x_{j}} \\
\hat{c} \approx y_{j}-\hat{\beta} * x_{j}
\end{gathered}
$$

Table 3 is basis for calculation of:

$$
\begin{gathered}
\hat{\beta} \approx \frac{-1.9713977-0.87877394}{5.65294-7.44425} \\
\hat{c} \approx 1.97139-1.591 * 5.65294=-11
\end{gathered}
$$

According to (19) and (20), the direction equation that approximates the expression (15) is (23):

$$
y=\beta * x+\hat{c}
$$


Figure 5 shows values from Table 3 in the form of graph. Values $y_{j}=y\left(t_{j}\right)$ and $x_{j}=x\left(t_{j}\right)$ are calculated from Eq. 23. Figure 6 is showing a comparison of the experimentally obtained data and the approximation based on the Weibull distribution. Based on the approximated data where $y=y(\hat{\beta}, \hat{c})$

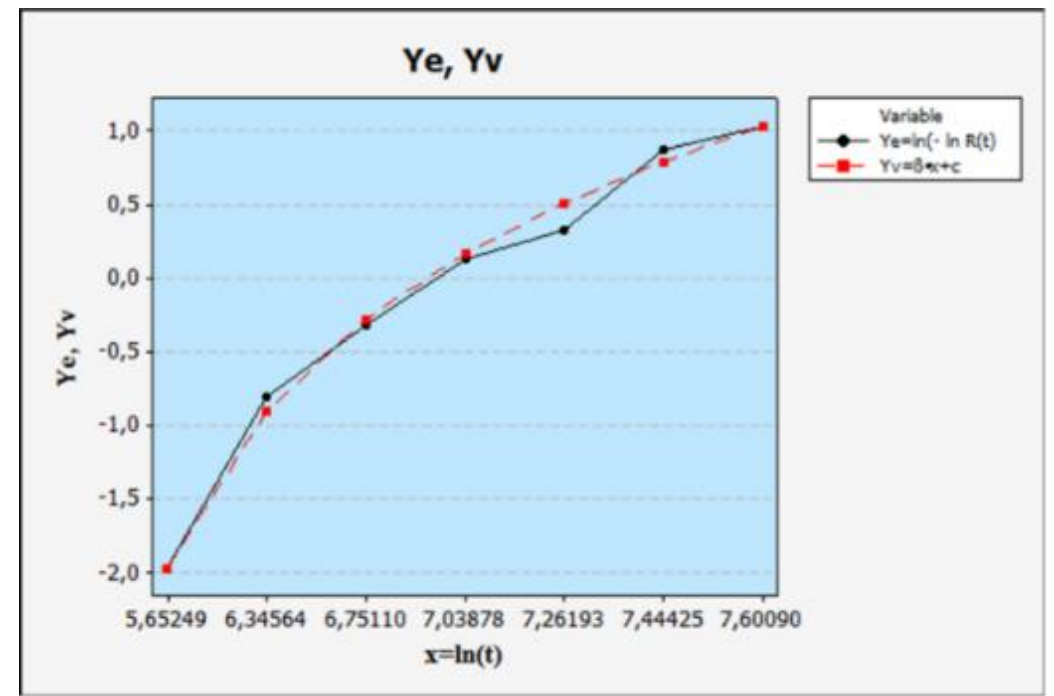

Figure 5. Values $y_{j i}, y_{j v}$.

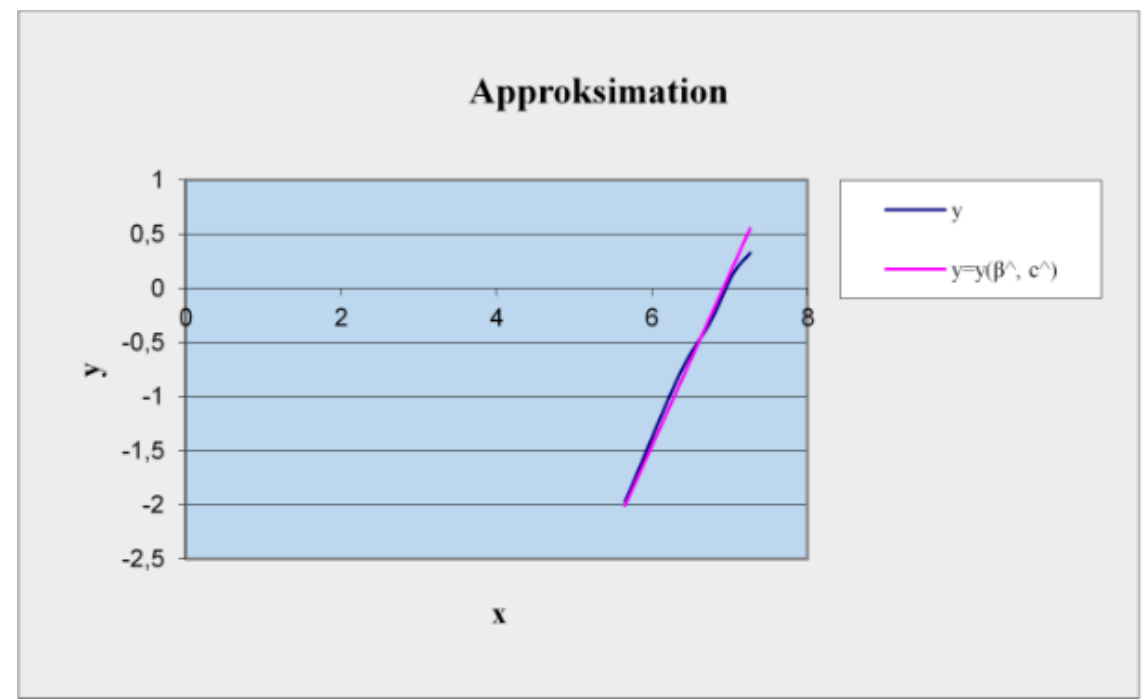

Figure 6. Approximation of data from the Weibull distribution.

and according to (18) follows:

$$
\eta=e^{-\frac{c}{\beta}}=e^{-\frac{-11}{1.591}}=e^{6.9139} \approx 1006[h]
$$

Following the above-mentioned, when failure density function has a Weibull distribution the expression, the reliability function of marine diesel engine $R_{v}(t)$ can be written:

$$
R_{v}(t)=e^{-\left(\frac{t}{\eta}\right)^{\beta}}=e^{-\left(\frac{t}{1006}\right)^{1.591}}
$$




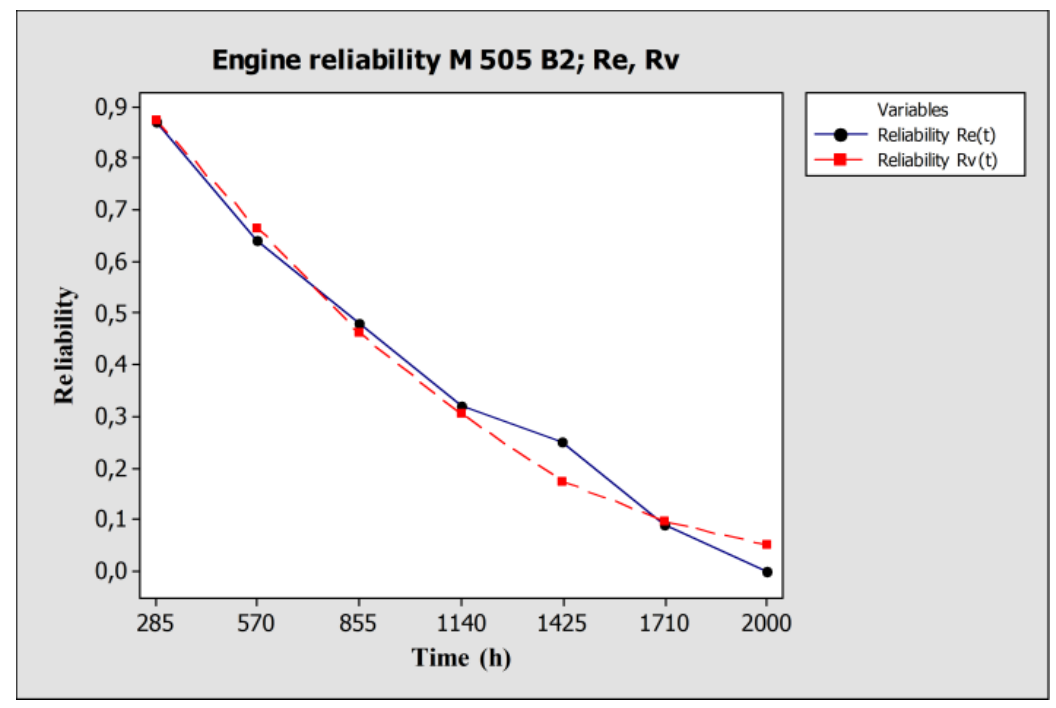

Figure 7. Reliability function $R_{e}(t)$ and $R_{v}(t)$.

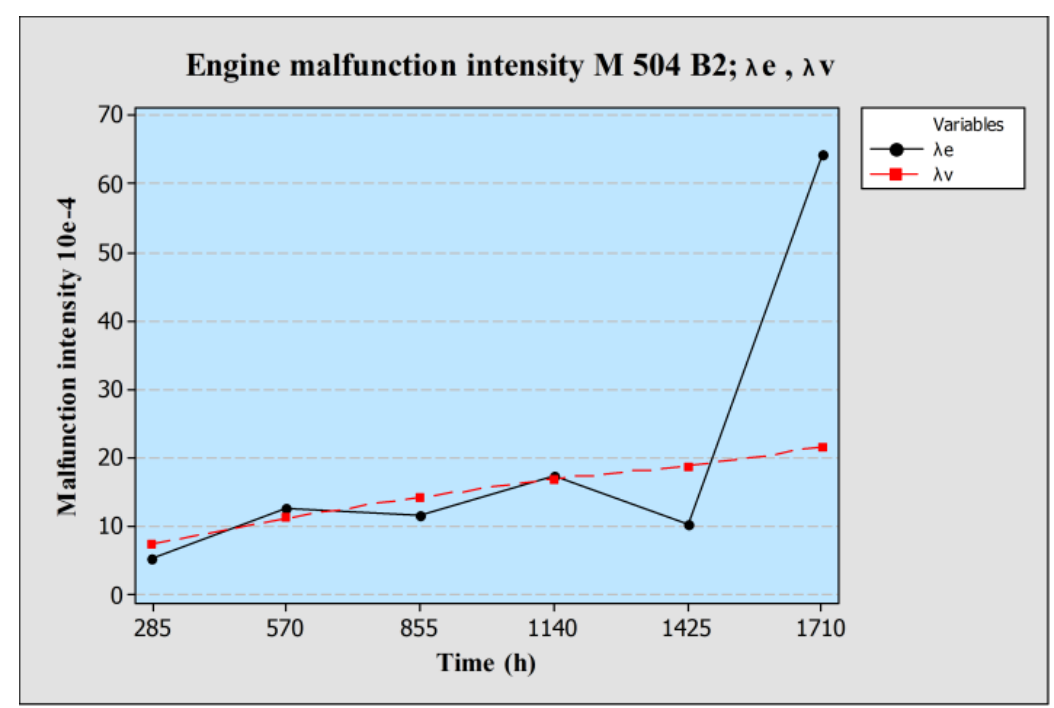

Figure 8. Malfunction intensity function $\lambda_{e}(t)$ and $\lambda_{v}(t)$.

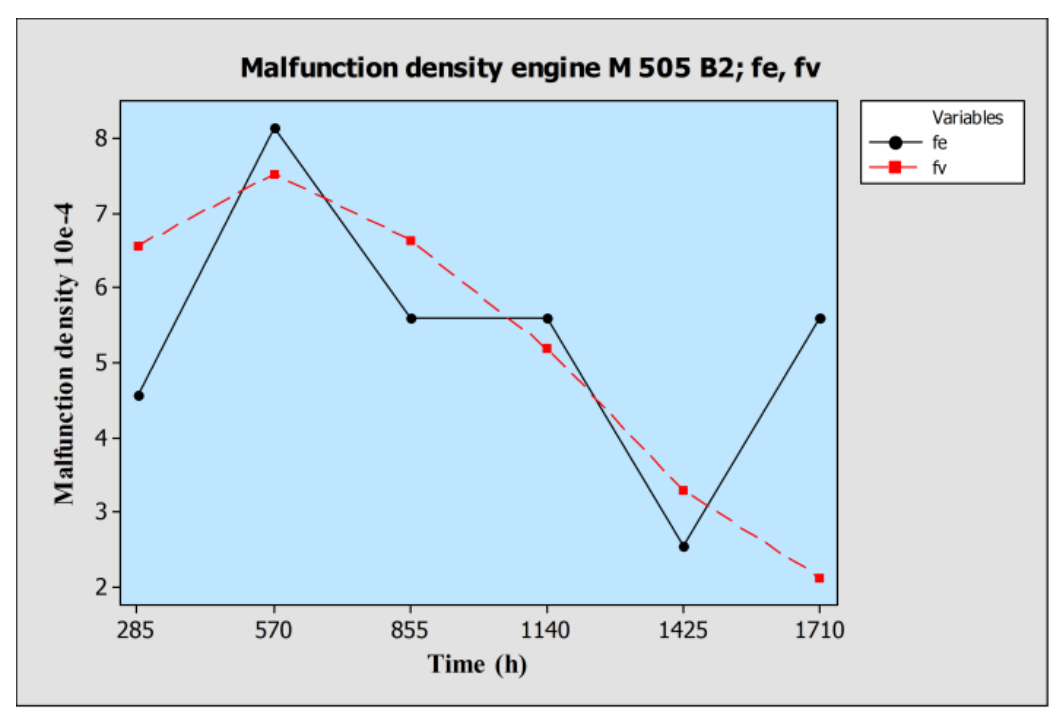

Figure 9. Malfunction density function $f_{e}(t)$ and $f_{v}(t)$. 
Figure 7, 8 and 9 show reliability function comparative graphs, malfunction intensity and density obtained on the experimental data basis and approximations based on the Weibull distribution.

\section{Evaluation of results and acceptance/rejection of the hypothesis}

According to the expression for calculation of the expected failure time $E(T)$, in case of the Weibull distribution, $E(T)$ amounts [16], [21]:

$$
E(T)=\gamma+\eta \Gamma\left(\frac{1}{\beta}+1\right)=902[h]
$$

According to Eq. 14 failure intensity of the expected failure time $E(T)$ amounts:

$$
\begin{gathered}
\lambda_{v}(t)=\frac{\beta}{\eta} * \eta \Gamma\left(\frac{t}{\eta}\right)^{\beta-1} \\
\lambda_{v}(t)=14.83 * 10^{-4}[\text { failures } / h]
\end{gathered}
$$

According to the experimental data in Table 2 malfunction intensity value $\lambda_{e}(902)$ can be approximately calculated by linear interpolation and therefore is valid:

$$
\begin{gathered}
R_{e s r}(902) \approx \gamma+\frac{\lambda_{e}(855)+\lambda_{e}(1140)}{2} \\
R_{e s r}(902) \approx 14.62 * 10^{-4}[\text { failures } / h]
\end{gathered}
$$

In the same mode it is possible to calculate $R_{v}(902), R_{e s r}(902), f_{v}(902)$ and $f_{e s r}(902)$.

$$
\begin{gathered}
R_{v}(902)=e^{-\left(\frac{t}{\eta}\right)^{\beta}}=0.4[h] \\
R_{e s r}(902) \approx \frac{R_{e}(855)+R_{e}(1140)}{2} \\
R_{e s r}(902) \approx 0.4[h] \\
f_{v}(902)=\lambda_{v}(902) * R_{v}(902) \\
f_{v}(902)=5.93 * 10^{-4} \\
f_{e s r}(902)=\lambda_{e s r}(902) * R_{e s r}(902) \\
f_{e s r}(902)=5.85 * 10^{-4}
\end{gathered}
$$

Table 4 presents the experimental data in relation to the data calculated on the basis of assumptions, (Hypothesis $H_{0}$ ), on the Weibull distribution, and it is determined by the difference between the experimental and calculated data. 
Table 4. Comparison of data.

\begin{tabular}{|c|c|c|c|c|}
\hline Data & Failure time & $\begin{array}{c}\text { Reliability } \\
R(t)\end{array}$ & $\begin{array}{c}\text { Malfunction intensity } \\
\lambda(t)\end{array}$ & $\begin{array}{c}\text { Failure density } \\
f(t)\end{array}$ \\
\hline Experimental & $M T B F_{b d s}=890[\mathrm{~h}]$ & $R_{\text {esr }}(902) \approx 0.4$ & $\lambda_{e s r}(350) \approx 14.62 \cdot 10^{-4}$ & $f_{e s r}(350) \approx 5.85 \cdot 10^{-4}$ \\
\hline Weibull distribution & $E(T)=902[\mathrm{~h}]$ & $R_{v}(T)=0.4$ & $\lambda_{v}(T)=14.83 \cdot 10^{-4}$ & $f_{v}(T)=5.93 \cdot 10^{-4}$ \\
\hline Difference & $12[\mathrm{~h}](1.34 \%)$ & $0.00(0 \%)$ & $0.21 \cdot 10^{-4}(1.43 \%)$ & $0.08 \cdot 10^{-4}(1.36 \%)$ \\
\hline
\end{tabular}

In order to confirm the hypothesis by subjecting experimental data reliability to the Weibull distribution, Kolmogorov-Smirnov test (K-S test) is performed [22]. According to the K-S test a theoretical model variable distribution can be accepted if it fulfils a condition:

$$
D_{\max }=\frac{d_{\alpha}}{\sqrt{n_{1 \max }}}
$$

For the selected risk level, the confidence parameter $\mathrm{d}$ can be taken from the tables [23]. In this case, the adopted risk level (confidence or significance) amounts to $\alpha=0.1$, and considering that $n_{l}=168$, calculation is:

$$
\frac{d_{\alpha}}{\sqrt{n_{1}}}=\frac{1.22}{\sqrt{168}}=0.094
$$

According to [22] and [23], the K-S test is performed with the data obtained during time period of normal use of the technical system. In the table [23] value for $D_{\max }$ can be taken and it amounts to $D_{\max }=0.075$. That value is compared with the value calculated by the expression (34):

$$
0.075<0.094
$$

In case of constant malfunction intensity, which would assume an exponential distribution of experimentally obtained data, Eq. 36 should be valid:

$$
\begin{gathered}
\lambda=\frac{1}{M T B F_{b d s}}=\frac{1}{890} \\
\lambda=11.23 * 10^{-4}[\text { cancellations } / h]
\end{gathered}
$$

The calculated malfunction intensity value is significantly less than the experimental value and the value calculated on the basis of the Weibull distribution assumption. This clearly indicates, and confirms the starting presumption that the results obtained from the reliability research of high-speed radial diesel engine M 504 B2 can be relevantly approximated by an exponential distribution.

\section{Data analysis using the Minitab software package}

The results obtained by the research were processed by computer using the Minitab software [18]. Usage of the statistical software will help (in determination) determining which distribution is the best approximation of the data obtained during the engine research. The software compares the data approximation among 14 different distributions in order to choose the most favorable distribution of the desired data. The most favorable distribution is selected on the basis of two statistical tests [24]:

- Anderson - Darling (AD) test [24], the minimum value of AD parameter indicates the most suitable distribution,

- $\mathrm{P}$ parameter, greater the value of $\mathrm{p}$ - parameter indicates the most favorable distribution to approximate the data. 
The data obtained from the analysis are presented in two forms, analytically and graphically (Figure 10 and 11). The presentation allows the choice of the most favorable distribution of experimental reliability of high speed diesel engine M504 B2 during the analyzed period.

\section{Goodness of Fit Test}

\begin{tabular}{lllll} 
Distribution & AD & P & LRT P & \\
Lognormal & 0.223 & 0.695 & & \\
Exponential & 0.437 & 0.517 & & \\
3-Parameter Weibull & 0.193 & $>0.500$ & 1.000 & \\
Weibull & 0.160 & $>0.250$ & & Threshold \\
& & & & \\
Distribution & Location & Shape & Scale & \\
Lognormal & -1.04220 & & 0.80728 & \\
Exponential & & & 0.44167 & \multirow{2}{*}{0.65013} \\
3-Parameter Weibull & & 4.61598 & 1.19392 & \\
Weibull & & 1.75281 & 0.49600 &
\end{tabular}

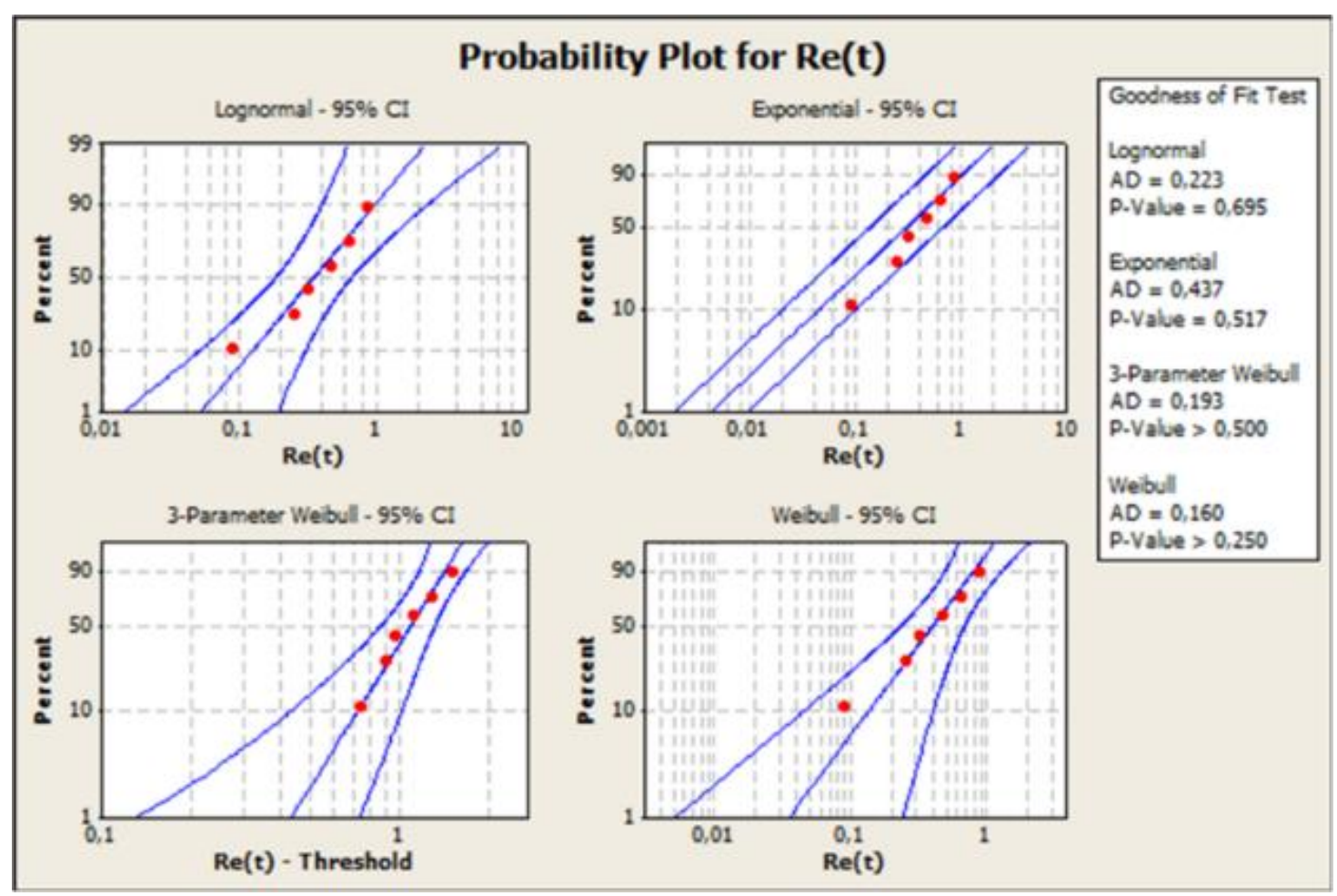

Figure 10. Probability distribution for $R_{e}(t)$. 


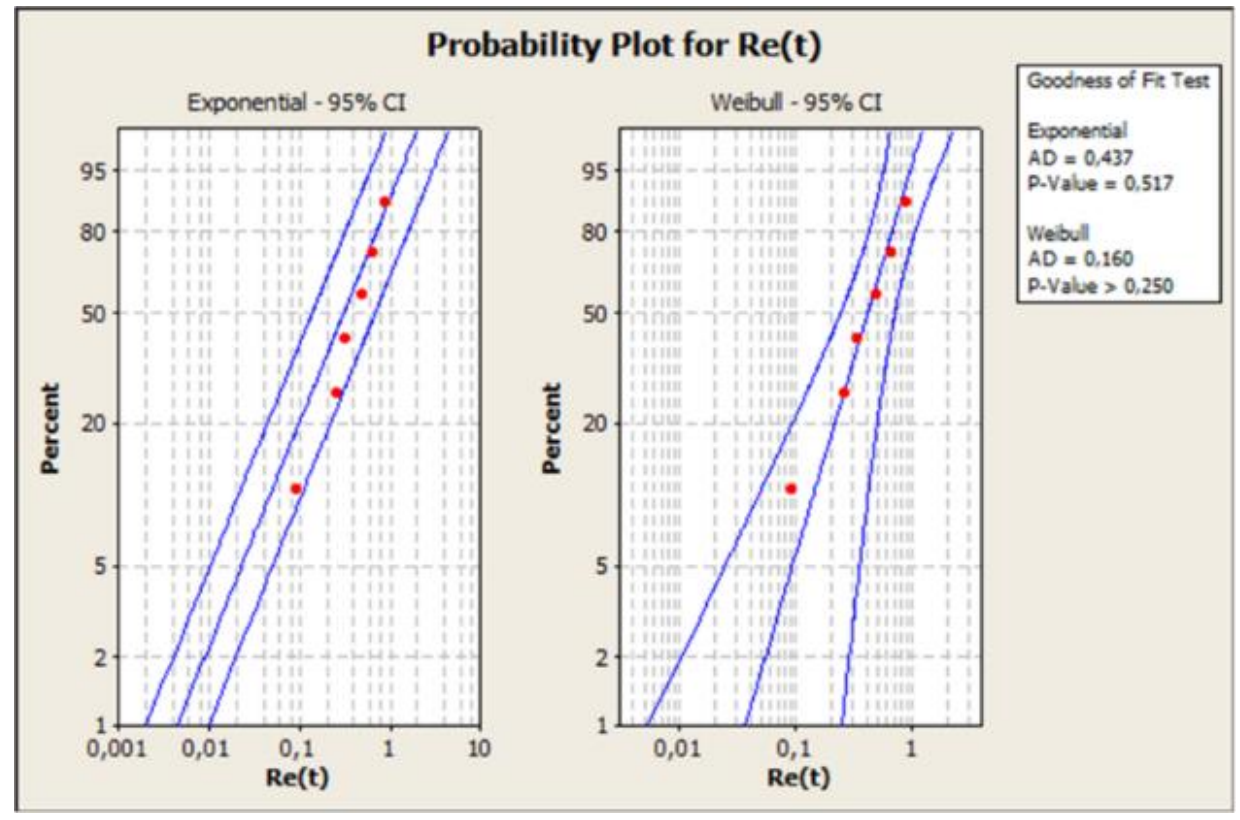

Figure 11. Weibull and Exponential distributions for $R_{e}(t)$.

Analyzing the results of a mathematical model obtained by using the Minitab software in graphical and analytical format (Figure 10 and Figure 11), it is visible that the Weibull reliability distribution is the best approximation of experimental data obtained from reliability research of high-speed diesel engine M 504 B2.

\section{Conclusion}

The hypothesis $H_{0}$ (Eq. 9) should be accepted when the following is considered:

- the data obtained by the analytical process shown in Table 2,

- the results of Kolmogorov-Smirnov test, and

- the results obtained by the analysis by the Minitab statistical software.

Reliability function $R(t)$ of high-speed diesel engine M 504 B2 is subjected to the law of the Weibull distribution and it is not possible to accept the assumption of a constant malfunction value, i.e. that the malfunction intensity is not time-dependent.

It is a common practice that when predicting a process of the technical system reliability one should start with the assumption of constant malfunction intensity. In the analyzed case, the so-called random malfunctions are present, whereas a random malfunction rate is not time-dependent.

It is also known that the malfunction intensity in most electronic parts of a technical system is constant i.e. time-independent. The carried out mathematical model of high-speed radial ship diesel engine M 504 B2 reliability points to the continuous increasing function of malfunction intensity and the fact that the reliability of the analyzed marine engine can be approximated by the Weibull distribution. The distribution, regardless of its complexity, should be used in practice when calculating reliability of similar engines, with a drop-down, constant and growing functions of the malfunction's intensity, enables a better depiction of the observed technical system, and the impact of aging of components on the system reliability as well.

Causes of malfunction of a marine diesel engine vary from engine overload and material fatigue, detrition and corrosion, to human factor. Further research is necessary to determine the mal-function intensity of subsystems of high-speed diesel engine M 504 B2 and to determine contribution of that intensity to the reliability and malfunction intensity of a high-speed diesel engine with a goal of a complete definition of malfunction intensity and reliability of high-speed diesel engine M 504 B2.

\section{References}

[1] Wolstenholme, L. (1999). Reliability Modelling, a Statistical Approach, New York: Routledge, USA. ISBN: 9781351419093.

[2] Zvezda: M 504 B2 instruction books, Leningrad. 
[3] Croatian navy: Engine Log Book, Split.

[4] Zvezda: High speed radial diesel engine M 504 B2 technical booklet, Leningrad.

[5] Baraldi, P., Di Maio, F., Genini, D., Zio E. (2015) Comparison of data-driven reconstruction methods for fault detection, IEEE Transactions on Reliability, Vol. 64 No. 3, 852-860, https://doi.org/10.1109/TR.2015.2436384

[6] Vanem, E., Brandsæter, A. (2019) Unsupervised anomaly detection based on clustering methods and sensor data on a marine diesel engine, Journal of Marine Engineering \& Technology, https://doi.org/10.1080/20464177.2019.1633223

[7] Dimopoulos, G.G., Georgopoulou, C.A., Stefanatos, I.C., Zymaris, A.S., Kakalis, N.M. (2014) A general-purpose process modelling framework for marine energy systems, Energy Conversion and Management, Vol. 86, 325-339, https://doi.org/10.1016/j.enconman.2014.04.046

[8] Brandsæter, A., Vanem, E., Glad, I. K. (2019) Efficient on-line anomaly detection for ship systems in operation, Expert Systems with Applications, Vol. 121, 418-437, https://doi.org/10.1016/j.eswa.2018.12.040

[9] Kanarachos, S., Christopoulos, S.-R.G., Chroneos, A., Fitzpatrick, M.E. (2017) Detecting anomalies in time series data via a deep learning algorithm combining wavelets, neural networks and Hilbert transform, Expert Systems with Applications, Vol. 85, 292-304, https://doi.org/10.1016/j.eswa.2017.04.028

[10] Chandola, V., Banerjee, A., Kumar, V. (2009) Anomaly detection: A survey, ACM Computing Surveys (CSUR), Vol. 41, No. 3, 15, https://doi.org/10.1145/1541880.1541882

[11] Jocanović, M., Šević, D., Karanović, V., Beker, I., Dudić, S. (2012) Increased efficiency of hydraulic systems through reliability theory and monitoring of system operating parameters, Strojniški vestnik - Journal of Mechanical Engineering Vol. 58, No. 4, 281-288, https://doi.org/10.5545/svjme.2011.084.

[12] Đurić, Ž., Josimović, Lj., Adamović, Ž., Radovanović, Lj., Jovanov, G. (2012): An Evaluation of Formed Maintenance Programme Efficacy, Strojniški vestnik - Journal of Mechanical Engineering Vol. 58, No. 5, 300-308.

[13] Croatian navy (2014). Missile gunboat launchers rule usage DPM - 103, Split.

[14] Popović, V., Vasić, B., Petrović, M. (2011): The Possibility for FMEA Method Improvement and Its Implementation into Bus Life Cycle, Strojniski vestnik - Journal of Mechanical Engineering, Vol. 56, No. 3, 179-185.

[15] Mihanović, L., Matika, D., Bernečić, D. (2015). High speed radial marine diesel engine maintenance suitability model. Scientific Journal of Maritime Research, Vol. 29, No. 2, 133-142, URI: https://hrcak.srce.hr/149660, accessed on 2020-01-20

[16] Vujanović, N. (1990). Reliability theory of technical systems, Military Publishing and News Centre, Belgrade.

[17] Ivanović, G., Stanivuković, D. (1983). Reliability of technical systems, University of Belgrade, Faculty of Mechanical Engineering in Belgrade, Belgrade.

[18] Minitab, http://www.minitab.com, accessed on 2020-01-20.

[19] Barle, J. (2018). Authorized lectures (unpublished, book in progress), Faculty of Electrical Engineering, Mechanical Engineering and Naval Architecture, Split.

[20] Majdančić, N. (1999). Strategije održavanja i informacijski sustavi održavanja, Slavonski Brod: Strojarski fakultet.

[21] Matika, D., Mihanović, L. (2011). Reliability of light construction high speed marine diesel engine, Shipbuilding: Theory and Practice of Naval Architecture, Marine Engineering and Ocean Engineering, No. 62, 28-36, URI: https://hrcak.srce.hr/67307, accessed on 2020-01-20.

[22] Jurjević, M. (2009). Simulation modelling of technical systems reliability using the system dynamics, Doctoral dissertation, FESB Split.

[23] Macek, M., Cvitković, B. (1987): Preliminary data for reliability and availability analysis of complex systems, Engineering Vol. 29, No. 3/4, 42-51.

[24] Razali, N.M., Wah, Y.B. (2011). Power comparisons of Shapiro-Wilk, Kolmogorov-Smirnov, Lilliefors and Anderson-Darling tests, Journal of Statistical Modelling and analytics Vol. 2, No. 1, 21-33. 